\title{
EL OMBUDSMAN MARROQUÍ O DIWAN AL MADALIM A LA LUZ DE LA EXPERIENCIA ESPAÑOLA
}

\author{
ABDELHAMID ADNANE \\ Profesor de Derecho Constitucional \\ Universidad Pablo de Olavide de Sevilla
}

\author{
SUMARIO \\ I. Notas introductorias. \\ II. Estatuto personal, organización y medios \\ del Wali Al Madalim. \\ III. Ámbito de competencia. \\ IV. Resolución de quejas: legitimación y \\ procedimiento. \\ V. Informes de Wali Al Madalim y de los \\ delegados. \\ VI. Reflexiones finales.
}

\section{NOTAS INTRODUCTORIAS}

Este trabajo pretende abordar los aspectos más relevantes del Diwan Al Madalim marroquí, teniendo muy presente la experiencia española en la materia; dos modelos diferentes que, como es sabido, responden a los presupuestos configuradores de cada sistema jurídico, y que, ineludiblemente, se traducen en unas concretas funciones que se esperan de este órgano en cada contexto.

Como primera providencia de acercamiento cabe apuntar que en el sistema jurídico marroquí esta institución hace resurgir de sus cenizas a otra aparecida en la época del segundo Califa musulmán, Omar Ibn Jatab (634-644), con el nombre de Diwan Al Madalim ${ }^{1}$ u oficina de quejas. En un principio, el término Diwan se utilizaba en el campo militar ${ }^{2}$ para referirse posteriormente

1 Dabir núm. 1.01.298, de 9 de diciembre de 2001, portant création de l'institution Diwan Al Madalim.

2 Inicialmente fue pensado para registrar las tropas, establecer sus sueldos así como de aquellos que habían prestado el servicio militar, y para ordenar los bienes del tesoro. 
a cualquier registro ${ }^{3}$; finalmente, evolucionó su sentido hasta confundirse con la propia oficina administrativa. Por otro lado, el término Al Madalim literalmente significa: abusos, excesos e injusticias. Podemos ver así que, desde sus primeros antecedentes, el sentido de esta institución es el de una oficina de quejas, cuyo titular es el Wali Al Madalim. Durante Reino de los Omeyas, este órgano se ocupaba "des redressement des abus" dando lugar a una dualidad de jurisdicciones: la de los Cadis competentes en materias civiles y penales, y la del Wali Al Madalim que resolvía en materia de abusos de poder cometidos por agentes de la Administración ${ }^{4}$. En la historia moderna, algunos autores $^{5}$ apuntan que durante el siglo XIX el gobierno marroquí se integraba por cinco Ministerios. A uno de los cuales, denominado el "Visirato de las reclamaciones", le correspondía esencialmente el control, e incluso la anulación, de los actos abusivos de las autoridades administrativas. Y en la segunda mitad del siglo XX, precisamente en 1956, se creó ante el Sultán una oficina de investigaciones y orientaciones para examinar las quejas presentadas, y que fue reemplazada por el actual Diwan Al Madalim creado por dahir ${ }^{\circ}$ 1.01.298 en diciembre de $2001^{6}$.

Su análisis, a pesar de ser una institución que se inscribe en una lógica tradicional monárquica de justicia y de preservación de los derechos de los ciudadanos $^{7}$, no puede hacerse al margen del nuevo marco de organización política revisado tras la formalización de los principios del constitucionalismo democrático a partir de 1962.

Pese a que la Constitución no lo menciona expressis verbis, encuentra su fundamento en el artículo 19 de la Constitución marroquí (en adelante, CM) ya que en su virtud fue dictado su dahir ${ }^{2}$ creador que, asimismo, regula sus aspectos principales.

3 HARSI, A., "Diwan Al Madalim ou Office de redressement des abus", Revue Marocaine d'Administration Locale et de Développement, n. ${ }^{\circ} 34,2002$, pág. 26.

4 Ídem, pág. 27.

5 LAHBABI, M., Le gowvernement marocain aux XIX siècle, Maghrébines, Casablanca, 1975, págs. 140 y ss

6 El Reglamento fue publicado en el Bulletin Officiel núm. 5174, de 1 de enero de 2004

7 BA MOHAMED, N., "La place de Diwan Al Madalim dans le droit comparé", Revue Marocaine d'Administration Locale et de Développement, n. ${ }^{\circ} 34$, 2002, pág. 14.

8 «El Rey, Amir Al Muminin, Máximo Representante de la Nación, Símbolo de su unidad. Garante de la permanencia y de la continuidad del Estado, vela por el respeto al Islam y a la Constitución. Es el protector de los derechos y libertades de los ciudadanos, grupos sociales y colectividades.

Garantiza la independencia de la Nación y la integridad territorial del Reino dentro de sus auténticas fronteras."

9 El Dahir es la forma jurídica para la producción de las normas jurídicas por parte del Monarca. El profesor Mohamed Achoukri señala que el término Dabir tiene un origen andaluz. «El Dahir sherif en el derecho público marroquí" (en árabe), Universidad de Casablanca, primera edición, 1983. Aclara que el Dahir ha conocido una continuidad en su uso desde los Merenides hasta la época Alauita, sin embargo destaca la existencia de momentos de discontinuidad optando en algunas ocasiones por el término "Verman" de origen otomano. 
De hecho, la articulación del referido Diwan fue anunciada en el discurso regio de diciembre de 2001 en el día mundial de los Derechos del Hombre. Su doble fuente de inspiración, tradicional por un lado y enriquecida por el derecho moderno por otro, es fácilmente palpable de la lectura de varios pasajes del discurso del monarca: «Ainsi, Nous consolidons les organes chargés, sous Notre protection, de redresser les iniquités, de faire valoir les droits et de sauvegarder les libertés, autant de missions qui comptent parmi les devoirs les plus sacrés du Roi, Amir Al Mouminine. Ce faisant, Nous suivons la voie tracée par Nos Glorieux Ancêtres qui se sont toujours attachés à créer et placer auprès de leur personne des institutions chargées de les tenir informés des injustices dont pouvaient pâtir leurs sujets, et de redresser les erreurs et abus éventuels, imputables aux responsables de l'administration". "Par ailleurs, en créant l'institution "Diwan Al Madhalim", Nous conférons une autre portée tangible à Notre concept de l'autorité, fondé sur la nécessité pour celle-ci d'être une autorité de proximité, au service du citoyen et du développement, attachée aux règles de primauté du Droit et de l'Equité".

No obstante, su carácter de proyección de las funciones del Imam de los creyentes, puede, e incluso debe, como queda apuntado, cobrar un nuevo sentido en el marco constitucional en cuyo seno funciona; labor que, indefectiblemente, nos obliga a traer a colación la razón de ser del Ombudsman en los Estados actuales.

Es bien conocido que si el Estado liberal de comienzos del siglo XIX se mantenía al margen de la vida social y sólo intervenía para la defensa de la seguridad y del orden público, de la libertad y de la propiedad, su nueva configuración como Estado social y de ahí, ineludiblemente, intervencionista en casi todas las esferas de la vida social, obliga a reforzar los medios clásicos de control de la Administración pública estableciendo nuevos modos de dar respuesta a los posibles agravios y problemas a los que puede dar lugar dicha expansión administrativa.

En este sentido, los Ombudsmen se perfilan como complemento a la jurisdicción contencioso-administrativa debido a la utilización restrictiva de la legitimación para accionar el proceso, al recurso a conceptos jurídicos indeterminados y a la desigualdad entre la Administración y el ciudadano a causa del incremento de sus potestades discrecionales, lo que genera verdaderas situaciones de indefensión. A ello se añade su configuración como medio institucional tendente a defender los derechos fundamentales heredados del constitucionalismo liberal y a hacer realidad los nuevos derechos de carácter básicamente prestacional recogidos en las diferentes Constituciones de la segunda mitad del siglo, y cuya efectividad depende, en gran parte, de la buena voluntad del legislador.

En suma, casi todas las defensorías del pueblo han roto con el clásico Ombudsman sueco que se limita a la supervisión de la actividad de la Administración desde el punto de vista de la mera legalidad. Quiere ello decir que al elenco de sus atribuciones — que incluye la tarea de impulso y persua- 
sión- se añade el control de la actividad legislativa. De lo que, en términos de Ollero, resulta su conversión en una institución juridicista ${ }^{10}$, proclive a la utilización de los medios judiciales, en lugar de una institución basada fundamentalmente en su capacidad persuasiva, y, consecuentemente, haciendo más sólido el sistema de control de los derechos y libertades.

\section{ESTATUTO PERSONAL, ORGANIZACIÓN Y MEDIOS DEL WALI AL MADALIM}

El Wali Al Madalim no es, a diferencia del modelo de "Ombudsman parlamentario" (en el caso español el Defensor del Pueblo es un Alto comisionado de las Cortes Generales ${ }^{11}$ ). una longa manus del Parlamento ${ }^{12}$.

Se trata de un órgano unipersonal nombrado por el monarca mediante dabir que le garantiza una autonomía funcional por un periodo de seis años renovables. Cabe la posibilidad, si es necesario, de una designación regia en el seno del Diwan de delegados a los que se atribuye la tarea de intermediar en asuntos particulares que afectan a la relación de ciertos ciudadanos con la Administración.

Es una magistratura de opinión que carece de fuerza coactiva directa en sus decisiones, siendo la persuasión y la autoridad moral, derivadas de su nombramiento regio, sus principales instrumentos.

Desde esta posición se le puede conceptuar como un órgano de control de la Administración Pública. Quiere ello decir que no desempeña una labor de freno sino de estimulador e impulsador de su función prestadora de servicios dentro del marco de un Estado social, en aras de una mayor realización de los derechos.

Al Wali, que ostenta también la calidad de miembro del Consejo Consultivo de los Derechos Humanos, se le faculta, previa autorización del rey, tanto para nombrar como para cesar a sus delegados ministeriales y regionales, quedando obligado a asegurarse de que cumplan su cometido con absoluta independencia e imparcialidad.

En cuanto a su estructura orgánica, se ha producido, debido a la enorme cantidad y variedad de asuntos a los que debe enfrentarse, y a semejanza de

10 Cit. por PÉREZ CALVO, A., I Jornadas sobre del Defensor del Pueblo andaluz, Serie Documentos Baeza, 18, 19 y 20 de Abril 2001. pág. 36.

$11 \mathrm{Su}$ procedimiento de designación se inicia con la propuesta de la Comisión Mixta Congreso-Senado de relaciones con el Defensor del Pueblo, por mayoría simple. El candidato propuesto debe ser ratificado por los Plenos del Congreso y del Senado, por mayoría de tres quintas partes de los miembros de ambas Cámaras y que de no alcanzarse dicha mayoría se reinicia el procedimiento siendo suficiente la mayoría absoluta en el Senado en la segunda fase.

12 En el caso francés, otro modelo referente en nuestro estudio, el mediador no es nombrado por el Parlamento sino por el Consejo de los Ministros, con el objetivo de reducir la apariencia de un control externo y así dotar de aceptabilidad a sus intervenciones por parte de la Administración. 
lo que ha ocurrido en España ${ }^{13}$, la aparición de toda una serie de órganos auxiliares. En este sentido, merece destacarse la Secretaría particular del Wali, un cuerpo de Administración central y un conjunto de delegaciones ministeriales y regionales.

La Administración central se compone de la unidad de consulta, la de coordinación entre delegaciones y de los servicios administrativos, financieros y técnicos.

La unidad de consulta, directamente subordinada al Wali, está integrada por consejeros elegidos según criterios de mérito y capacidad en las áreas relacionadas con la acción del Wali. A este órgano le corresponde informar sobre las cuestiones planteadas y emprender, a instancia del Wali, toda labor investigadora con relación a los asuntos a resolver.

La unidad de coordinación entre delegaciones, presidida por el Wali y cuyo trabajo es supervisado directamente por él, se compone de un consejero coordinador general y de consejeros encargados de secciones en la Administración central. Su tarea consiste en ser el vaso comunicante de las diferentes delegaciones ministeriales y regionales, permitiendo la normalización de sus procedimientos de trabajo y constituyéndose como referencia para el normal cumplimiento de sus funciones.

Los servicios administrativos, financieros y técnicos se dividen en varias secciones. Se encargan de la administración de los recursos humanos, la elaboración y ejecución del presupuesto de la institución. Asimismo deben realizar los estudios e investigaciones relacionados con la actividad de la institución y asegurar el seguimiento de las reclamaciones y quejas. A dichos servicios corresponde también la elaboración de los Informes correspondientes a la actividad del Diwan, el tratamiento informático, estadístico y la promoción de la comunicación, la cooperación con los organismos de defensa de los derechos e intereses de los ciudadanos así como la formación para el perfeccionamiento del personal al servicio del Diwan.

Las delegaciones ministeriales ${ }^{14}$, dirigidas cada una por un delegado ministerial del Wali, pueden constituirse ante cada ministerio o ante un conjunto de ministerios. En cuanto a las delegaciones regionales, que funcionan bajo la autoridad de un delegado regional, se crean en cada provincia o prefectura capital de región. Las atribuciones y la organización interna de sus unidades dependientes son fijadas por decisión del Wali Al Madalim.

13 El Defensor del Pueblo puede designar libremente los asesores que estime necesarios para el ejercicio de sus funciones dentro de los límites presupuestarios. Dichos asesores cesarán automáticamente en el momento de la toma de posesión de un nuevo Defensor del Pueblo designado por las Cortes. El Defensor del Pueblo podrá estar asistido por un Gabinete Técnico, bajo la dirección de uno de los Asesores, correspondiendo a dicho Gabinete organizar y dirigir la Secretaría particular del Defensor del Pueblo, realizar los estudios e Informes que se le encomienden y ejercer las funciones de protocolo.

14 Art. 26 del Reglamento Interior del Diwan Al Madalim: "Cada delegación ministerial o regional será formada por: La unidad de acogida y la oficina de orden, la unidad de recepción de las reclamaciones, quejas y solicitudes de arreglo, la unidad de indagación e investigación, la unidad de estudios e Informes y la unidad de asuntos administrativos." 
El personal de la institución del Diwan Al Madalim, que asiste al Wali en sus funciones, se compone de los delegados, los consejeros ${ }^{15}$, los comisionados $^{16}$, los encargados de estudios ${ }^{17}$, los cuadros administrativos y técnicos ${ }^{18}$.

Los delegados ministeriales y los delegados regionales — cuya situación administrativa y régimen de indemnización viene fijado por decisión del Wali-son designados por él mismo previa autorización del monarca entre las personas pertenecientes a los cuadros superiores del Estado, de los establecimientos públicos o del sector privado que acrediten un nivel superior de formación y de experiencia profesional en los campos jurídico, judicial, administrativo o financiero, y reputados tanto por su integridad y competencia como por su pericia.

A diferencia del modelo español que habilita a las Cortes Generales a fijar de forma discrecional una dotación económica, configurada como partida dentro del presupuesto de las mismas, los recursos para atender los gastos de funcionamiento y de equipamiento del Diwan Al Madalim provienen de las partidas previstas para ello en el presupuesto de la Corte Real. El Wali, titular del órgano, es el responsable de la elaboración del proyecto de presupuesto y de su ejecución, una vez aprobado, de acuerdo con la normativa relativa a la organización financiera y contable del Diwan.

\section{III. ÁMBITO COMPETENCIAL}

Parece oportuno distinguir al abordar el ámbito competencial del Diwan Al Madalim, entre un ámbito subjetivo y otro objetivo.

Por lo que al primero de los puntos hace referencia hay que señalar que la competencia subjetiva del Diwan Al Madalim viene determinada por su re-

15 Art. 64 R.I.: "Los consejeros serán nombrados entre: Los candidatos pertenecientes a los cuadros administrativos y técnicos superiores clasificados al menos en la escala de remuneración n. ${ }^{\circ} 11$ o entre los cuadros semejantes, teniendo en su haber al menos 10 años de servicios efectivos en una Administración pública en esta calidad.

Los candidatos profesores investigadores de la enseñanza superior que tengan cumplidos al menos 5 años de servicios efectivos."

16 Art. 65 R.I.: «Los comisionados serán nombrados entre los candidatos pertenecientes a los cuadros administrativos y técnicos superiores clasificados al menos en la escala de remuneración n. ${ }^{\circ} 11$ ó en un cuadro semejante y que tengan cumplidos al menos 5 años de servicios efectivos en una Administración pública en esta calidad."

17 Art. 66 R.I.: "Los encargados de estudios serán nombrados entre: Los candidatos con un título que permita el acceso a un cuadro clasificado al menos en una escala de remuneración n. ${ }^{\circ}$ 11 ó a un cuadro semejante. Los candidatos pertenecientes a los cuadros de las administraciones públicas clasificados al menos en la escala de remuneración n. ${ }^{\circ} 11$ y tengan cumplidos al menos dos años de servicios efectivos en una Administración pública."

18 Art. 67 R.I.: “Los cuadros administrativos y técnicos serán nombrados entre los candidatos que cumplan las mismas condiciones que las exigidas para los cuadros similares en las administraciones del Estado. Los jefes de secciones y los jefes de unidades serán nombrados respectivamente entre los consejeros y comisionados, mencionados en los arts. 64 y 65 citados anteriormente." 
glamento interno ${ }^{19}$ que extiende sus ámbitos de actuación a las Administraciones del Estado, las entidades locales, los entes públicos o los organismos que disponen de prerrogativas de potestad pública. Dicho en otros términos, alcanza a toda persona moral competente para tomar una decisión recurrible por la vía del contencioso administrativo.

Los delegados ministeriales ejercen sus atribuciones ante los Ministerios, establecimientos públicos bajo su tutela y organismos que ostentan prerrogativas de potestad pública a nivel central siendo vertical su acción en su seno.

Cada delegado regional, cuya tarea es de carácter horizontal, desempeña su labor ante las entidades locales y el conjunto de los servicios exteriores del Estado, de los establecimientos públicos, y de los organismos que gozan de prerrogativas de potestad pública radicados en la zona territorial de la región en cuya capital ha sido designado.

Con relación al segundo de los puntos, ámbito objetivo, debe destacarse, como ha quedado anotado, que en el derecho comparado la evolución del ombudsman ha obligado a que su labor, inicialmente de supervisión de la actividad administrativa, se extendiera a la defensa de los derechos fundamentales. Este cambio, protagonizado por el proveedor portugués, ha sido implantado por el legislador orgánico español al incluir en la normativa de desarrollo de la institución del Defensor del Pueblo competencias garantistas de dichos derechos ${ }^{20}$. Ello hace que su labor de control sea total ${ }^{21}$, incluyendo normas con rango de ley, reglamentos, actos, vías de hecho y omisiones de los sujetos controlados. Quedan excluidas las quejas formuladas por una autoridad administrativa referidas a asuntos de su competencia, o aquellas que dejen entrever mala fe en su presentación o que no guarden relación con un interés público protegible. Tampoco resultan admisibles los asuntos relativos a hechos en los que no haya tomado parte, ni directa ni indirectamente, la Administración Pública. No huelga recordar que la Constitución española legitima al Defensor del Pueblo para interponer ante el Tribunal Constitucional tanto el recurso de inconstitucionalidad como el recurso de amparo, convirtiéndose así en el único órgano del Estado habilitado para accionar ambos procedimientos. Esta legitimación le permite reaccionar frente a cualquier actuación vulneradora de derechos proveniente de cualquier poder público. Asimismo su Ley Orgánica lo legitima para ejercitar la acción de responsabilidad de autoridades y funcionarios.

A diferencia de este modelo, en la norma marroquí el Diwan Al Madalim se limita a conocer de las reclamaciones y las quejas cuya pretensión principal es la reparación de un daño, un perjuicio, un abuso o una infracción de las reglas de la primacía del derecho y de la equidad. De igual modo, sólo le co-

19 Art. 2 R.I.: "Los delegados ministeriales y regionales ejercen sus competencias bajo la autoridad de Wali Al Madalim de conformidad con las disposiciones del dahir $\mathrm{n}^{\circ} 1.01 .298 \mathrm{y}$ en el marco de las atribuciones, modalidades y condiciones previstas en el presente reglamento".

20 ESCOBAR ROCA; G.,Defensorias del pueblo en Iberoamérica, op. cit. pág. 176.

21 Vid. Arts. 9.1, 23 y 28.1 de la LODP. 
rresponde atender a las solicitudes de arreglo cuya meta es la búsqueda de una solución rápida, equitativa y amistosa del litigio planteado con la Administración.

Entiéndase incluidas en este ámbito las infracciones cometidas y los daños irrogados tanto por actos como por omisiones de la Administración. De ello se sigue que el Diwan debe perfilarse como órgano dotado también de capacidad para advertir y recomendar acciones positivas a los entes administrativos silentes respecto a las solicitudes de los ciudadanos.

En un nivel inferior, además de la recepción e instrucción de las quejas y solicitudes de arreglo que se le someten dentro del ámbito subjetivo de sus competencias, a los delegados ministeriales y regionales les incumbe promover la comunicación entre la Administración y los ciudadanos, dando a conocer la institución en la sociedad y sirviendo, en su caso, de enlace entre el Diwan y las diferentes Administraciones. Igualmente se les faculta para someter al Wali Al Madalim las propuestas y recomendaciones con vistas a optimizar el funcionamiento del aparato administrativo a través de nuevos procedimientos de acogida y de la simplificación de los procedimientos administrativos, y a paliar las dificultades con las que pueden encontrarse los ciudadanos en su relación con la Administración.

Quedan exceptuadas del examen e instrucción del Wali Al Madalim y de sus delegados las quejas sometidas a conocimiento del poder judicial, las denuncias sobre cuyo objeto haya recaído una sentencia judicial firme así como los asuntos que competen a la institución parlamentaria. Semejante restricción afecta a las cuestiones que, siendo de su competencia, no se hayan accionado los procedimientos judiciales previstos para su protección.

De igual modo, y a diferencia de la mayoría de muchas defensorías del pueblo, consideradas según la expresión de Pérez royo como "garantías orgánicas" de los derechos fundamentales, sólo le cabe al Wali Al Madalim elevar al Consejo Consultivo de los Derechos Humanos ${ }^{22}$ aquellas quejas y denuncias relativas a violaciones de los Derechos Humanos ${ }^{23}$.

A pesar de estas limitaciones, tanto el Wali Al Madalim como sus delegados pueden, en virtud de su función mediadora buscar, siempre a instancia de parte, las soluciones tendentes a dar una solución rápida y equitativa al litigio.

22 El Consejo Consultivo de Derechos Humanos fue creado el 8 de mayo de 1990 y reorganizado el 11 de abril de 2001. Sus competencias consultivas se concretan en que puede aprobar dictámenes relativos a la conformidad o no de las normas internas con los tratados internacionales sobre Derechos Humanos y conocer de las quejas que se le presenta por motivo de violaciones de Derechos Humanos. A este respecto, puede proponer al Ejecutivo la necesariedad de un resarcimiento a las víctimas de dichas violaciones.

23 El número de quejas que afectan a los derechos hummanos, recibidos por el Diwan y transmitida al Consejo Consultivo de los Derechos Humanos ha experimentado un notable aumento en comparación con el año 2005, pasando de 34 a 74 quejas en 2006 y alcanzó el número de 91 en 2007. En " Rapport d'activité de Diwan Al Madalim Au titre des années 2006 et 2007 Soumis par Wali Al Madalim à la Haute Appréciation de Sa Majesté le Roi Amir Al Mouminine Mohammed VI ": http://www.diwan-almadhalim.ma/admin/download/upload/Rapport20062007.pdf 
De todos modos, el recurso al Diwan Al Madalim no interrumpe ni suspende los plazos de prescripción y de recurso previstos por la normativa correspondiente.

Cabe asimismo anotar que si bien el ejercicio de la potestad jurisdiccional en ningún caso resulta fiscalizable por esta institución, existen algunos aspectos de la Administración de justicia que sí pueden estar sujetos a un control indirecto. Dicho en otros términos, si en virtud del principio de la independencia judicial la intervención del Wali Al Madalim, igual que la del Defensor del Pueblo $^{24}$, no debe bajo ningún concepto incidir sobre la función de administrar justicia, ello no es óbice para que su ámbito competencial alcance a la administración de la Administración de justicia. Entendida ésta como el funcionamiento material de la Administración de justicia en cuanto servicio público cuyas disfunciones pueden mermar el pleno y efectivo ejercicio de los derechos.

En el modelo jurídico español, sin perjuicio de lo establecido en los artículos 23 y 28.2 de LODP, los artículos 54 de la Constitución y 9.1 LODP establecen tanto a los derechos del título primero como a los principios constitucionales de la Administración pública ${ }^{25}$ como parámetros de control. En cuanto al orden jurídico marroquí, se considera, en el artículo 5 del dahir creador del Diwan Al Madalim, al funcionamiento de las Administraciones ajustado a las reglas de primacía del derecho como parámetro de control formal, y como canon de control material, a semejanza de su homólogo francés, remite a los principios de equidad, lo que lleva a deducir una implementación indirecta de los Derechos Humanos mencionados en el preámbulo de la norma suprema marroquí26.

Dicha previsión expresa de una intervención en equidad habilita al Wali Al Madalim para sugerir a la Administración descartar cualquier interpretación estrictamente literal de las normas que podría dar lugar a una aplicación antisocial del Derecho, y adoptar soluciones socialmente eficaces con base en una interpretación no impeditiva del disfrute de los derechos.

\section{RESOLUCIÓN DE QUEJAS. LEGITIMACIÓN Y PROCEDIMIENTO}

Si el mediador francés, con el que suele compararse el Diwan Al Madalim, no puede recibir quejas directamente de los ciudadanos, debiendo éstos encauzarlas a través de diputados o senadores, lo que a la postre no es más que un filtro político, en la norma marroquí la legitimación para acceder es

24 Vid. artículo 13 LODP.

25 Dispone el artículo 103.1 de la Constitución española que: "La Administración Pública sirve con objetividad los intereses generales y actúa de acuerdo con los principios de eficacia, jerarquía, descentralización, desconcentración y coordinación, con sometimiento pleno a la ley y al Derecho."

26 "Consciente de la necesidad de colocar su acción en el marco de los organismos internacionales, en que se integra en tanto que miembro activo y dinámico, el Reino de Marruecos subscribe los principios, derechos y obligaciones que emanan de las cartas de dichos organismos y reafirma su adhesión a los Derechos Humanos tal como son universalmente reconocidos". 
más amplia ${ }^{27}$. De hecho, puede dirigirse ${ }^{28}$ al Wali o a sus delegados toda persona física o moral de derecho privado estableciéndose la acreditación un interés legítimo como requisito procesal.

La legislación española operando del mismo modo apostrofa en el artículo 10.1 LODP, con objeto de ampliar al máximo el espectro de legitimados para acceder al Defensor del Pueblo, que no podrán constituirse como impedimento la nacionalidad, la residencia, el sexo, la minoría de edad, la incapacidad legal del sujeto, el internamiento en un centro penitenciario o de reclusión o, en general, cualquier relación de dependencia de una Administración o Poder Público. A mayor abundamiento, la referencia al interés legítimo, alegable dentro del plazo fijado en un año ${ }^{29}$, no es óbice para que el Defensor del Pueblo actúe de oficio.

La noción de interés legítimo no está reñida con los principios de antiformalismo y la mayor generosidad y flexibilidad que deben caracterizar las vías de acceso al Ombudsman. Ello no obstante, dichos principios deben conjugarse con un razonable criterio de determinación de unos mínimos para dicho acceso $^{30}$. Parece preciso así que se prevea algún límite en cuanto a la legitimación para acceder en queja al Defensor ${ }^{31}$.

La gratuidad, en aras de facilitar el acceso al Ombudsman, es una característica común a ambos modelos institucionales. De hecho, el artículo 32 del reglamento del Diwan la establece tanto para la presentación de reclamaciones o quejas y solicitudes de arreglo como para la intervención del Wali y de sus delegados. Este recurso puede efectuarse directamente en el Diwan o ante los delgados sea por correo ordinario o certificado o incluso por cualquier otro medio. De igual modo, no será preceptiva la asistencia de letrado ni de procurador ${ }^{32}$ para la presentación de quejas por cuanto el trámite es sumamente simplificado siendo suficiente un simple escrito firmado que contenga, detalladamente, el asunto de que se trate, el nombre, apellidos y el domicilio del peticionario.

Para ser admitidas a trámite 33 las reclamaciones o quejas ${ }^{34}$ y las solicitudes de arreglo, presentadas ante el Diwan Al Madalim, que de ningún modo pue-

27 Véase http://www.diwan-almadhalim.ma/admin/download/upload/Rapport2006-2007.pdf.

28 Artículo 34 del Reglamento Interior del Diwan Al Madalim

29 Vid. artículo 15.1 LODP.

En el mismo sentido, el artículo $9^{\circ} .1$ de la LODP faculta al Defensor para iniciar y proseguir de oficio cualquier investigación conducente al esclarecimiento de actos y resoluciones administrativas. Esta actuación, a diferencia de la que se sigue a instancia de parte, no está sujeta a plazo alguno.

30 A. GIL-ROBLES: «El Defensor del Pueblo», Cuadernos Civitas, Madrid, 1979, pág. 91.

31 F. FERNÁNDEZ SEGADO, «El Estatuto Jurídico-Constitucional del Defensor del Pueblo en España", op. cit., pág. 272.

32 Artículo 15.2 LODP.

33 El porcentaje de las quejas admitidas ha aumentado de manera significativa. Así, el porcentaje de las quejas admitidas ha experimentado un aumento sensible: $29 \%$ en 2004, 46\% en 2005 para alcanzar el 78\% en 2006 y el 91\% en 2007.

34 Artículo 38 del Reglamento Interior del Diwan Al Madalim: "Las quejas y las reclamaciones escritas u orales son anotadas y numeradas en el registro del Wali Al Madalim o de su delegado en un registro creado al efecto." 
den contener expresiones injuriosas o difamatorias, deben ser escritas con indicación de los datos personales y de domicilio y, tratándose de una persona moral, de su denominación, naturaleza, sede y representante legal. De ahí la inadmisión de las reclamaciones y quejas anónimas. Se precisa, además, identificar la Administración contra cuyo acto se dirige la pretensión, no siendo admisibles las quejas relativas a los litigios entre las Administraciones.

A todo ello ha de agregarse una breve relación, firmada por el interesado o por su apoderado, de las gestiones llevadas a cabo por el requirente para hacer valer sus derechos, así como una declaración jurada de que del asunto no está conociendo ningún tribunal ni tampoco ha sido objeto de pronunciamiento judicial alguno ${ }^{35}$. Dicho requisito pretende compatibilizar el Diwan con la justicia administrativa haciendo que el primero sea complementario de la segunda con objeto de amalgamar legalidad con justicia.

En caso de que las reclamaciones, quejas o solicitudes de arreglo sean presentadas por un grupo de personas unidas por la defensa del mismo interés debe mencionarse, además de las indicaciones anteriormente descritas, la identidad de todos los demandantes y sus firmas o, en su caso, la de su representante.

De igual modo que el legislador español que prevé, en caso de extrema urgencia, la eventualidad de comunicación de la queja por vía telefónica, o por cualquier otro medio de comunicación, siempre que el interesado la amplíe posteriormente por escrito firmado ${ }^{36}$, el artículo 37 del Reglamento del Diwan abre la posibilidad a la presentación verbal de las quejas y su transcripción en un acta que contendrá todas las menciones y las indicaciones previstas para la forma escrita.

La tramitación de las quejas y reclamaciones se preludia por un estudio preliminar tendente a comprobar el cumplimiento de los requisitos exigidos y a asegurarse de su competencia, que debe, en caso de inadmisión, culminar con una decisión motivada alegando su incompetencia que será notificada de inmediato al requirente. Asimismo puede decretar el archivo del expediente que, aun siendo admisible, no reúne los elementos que justifiquen su intervención.

Si el órgano instructor, sea el Wali o su delegado, declina la demanda por versar sobre violación de los Derechos Humanos, debe ineludiblemente ponerlo en conocimiento del Consejo Consultivo de los Derechos Humanos en aplicación del artículo 41 del Reglamento del Diwan ${ }^{37}$.

Artículo 39 del Reglamento Interior del Diwan Al Madalim: "Se enviará inmediatamente al requirente un acuse de recibo de la queja haciendo mención de la fecha y del número de registro".

35 Artículo 43 del Reglamento Interior del Diwan Al Madalim: "Wali Al Madhalim, o su delegado, puede pedir a las partes concernidas toda indicación y explicación complementarias, documento o pieza que estime necesaria para dar curso a la queja que le ha sido presentada".

36 La correspondencia dirigida al Defensor del Pueblo español remitida por reclusos, o las posibles conversaciones telefónicas que pudieran mantenerse en este caso, no pueden ser objeto de ningún tipo de censura.

37 Dispone el artículo 41 del Reglamento Interior del Diwan Al Madalim que "(s)i se aprecia que la queja está fuera del ámbito competencial del Wali Al Madalim o si no cumple los requi- 
Quede dicho que ninguna investigación, en coherencia con la peculiar naturaleza del procedimiento, debe afectar la ejecutoriedad de los actos y resoluciones administrativas, ni suponer una sustitución, suspensión o ampliación de las vías y plazos para recurrir los mismos. Ello se debe a que los principios procesales que presiden la actuación del Ombudsman han de compaginarse con el principio de seguridad jurídica.

Con anterioridad a toda labor investigadora y de averiguación ${ }^{38}$, el órgano de referencia puede, según las circunstancias del caso, instar a las partes a que opten por una solución amistosa, o emprender directamente diligencias de mediación según criterios de equidad. En este último caso, su actuación no consiste en escuchar a las partes en aras de formular propuestas que permitan alcanzar un acuerdo satisfactorio para ambas, sino que debe limitarse a informar a una de ellas: al ciudadano en caso de que su pretensión fuera injustificada, o a la Administración recordándole que el ordenamiento jurídico prevé una solución alternativa a la que ha dado al caso litigioso, por lo que debe satisfacer, total o parcialmente, la pretensión del requirente.

En el procedimiento previsto por la norma española la investigación es, a su vez, rápida y carente de formalidades. De hecho, se dirige a la dependencia concernida, bien por escrito solicitando información sobre el caso y la documentación correspondiente, o acudiendo él mismo o a través de un asesor en quien delegue esta tarea para efectuar las comprobaciones de modo personal in situ. El procedimiento más habitual para concluir las reclamaciones es la mediación entre los ciudadanos y la Administración. Comúnmente, el arreglo se produce por la vía de la conciliación debido a la fluidez de las relaciones entre el Defensor del Pueblo y la Administración ${ }^{39}$.

Volviendo a la institución marroquí, la tarea mediadora del Wali deriva tanto de sus funciones como del modo de abordar los problemas que se le plantean. En efecto, si en muchos países se contemplan la conciliación y la mediación con un carácter facultativo, el Wali al Madalim coadyuva a la formación de la resolución final del procedimiento que las partes van a formular de mutuo acuerdo, llevando a cabo cuantas actuaciones de avenencia fueran precisas para llegar a un resultado final que las partes pactan de mutuo acuerdo. Aunque dicho acuerdo fuera patrocinado por el Wali su contenido carece de fuerza vinculante, eso es de la facultad de coertio consustancial a

sitos para ser admitida a trámite, el Wali o su delegado emite una decisión motivada indicando que la queja, según el caso, es inadmisible u opone su falta de competencia. Esta decisión es inmediatamente notificada al requirente. El Wali o su delegado puede orientar el requirente hacia la autoridad competente salvo que se trate de quejas relativas a violaciones de Derechos Humanos en aplicación de las disposiciones del primer apartado del artículo 6 del dahir 1.01.298 precitado".

381020 quejas han sido derivadas durante el periodo 2006-2007 a las autoridades competentes.

39 F. BALAGUER CALLEJÓN (Coordinador), Manual de Derecho Constitucional, Vol II, Tecnos, Madrid, Tercera edición 2008, pág. 362. 
cualquier órgano jurisdiccional, lo que constituye un verdadero límite a su acción mediadora.

De todos modos la labor del mediador, de quien se predica la imparcialidad respecto de las partes, debe respetar el secreto profesional que, además de redundar en beneficio de su reputación, resulta ser una garantía a las partes para exponer con sinceridad todo lo relacionado con el litigio. Dicha función se ve, si lugar a dudas, favorecida por la falta de un procedimiento rígido, común en la jurisdicción.

Frustradas las diligencias de mediación, el Defensor del Pueblo español puede adoptar varias resoluciones ${ }^{40}$. La primera consiste en sugerir a la Administración concernida la modificación de los criterios utilizados en la actuación administrativa. Para ello se dirige al superior jerárquico cuando se aprecia la existencia de un presunto abuso, arbitrariedad, discriminación, error, negligencia u omisión por parte del funcionario. Otra posibilidad reside en proponer al Gobierno o las Cortes Generales, según el caso, la modificación de las normas cuyo cumplimiento riguroso pueda provocar situaciones injustas o perjudiciales para los administrados. La tercera vía sería la de formular una solicitud a las Administraciones Públicas instándoles a activar los mecanismos de inspección y sanción, o, en su caso, dirigir directamente a las autoridades y funcionarios advertencias, recordatorios y sugerencias en relación con sus actuaciones administrativas. Por último, puede elevar al conocimiento del Ministerio Fiscal los hechos presuntamente delictivos que hayan podido apreciarse con ocasión de su investigación.

A su vez, la normativa marroquí prevé que cuando la labor mediadora se revela ineficaz, se incoa un expediente de investigación en aras de establecer la realidad de los hechos debiendo culminar con la redacción de un Informe de conclusiones. A continuación, remite la queja a la Administración concernida que, en un plazo de un mes prorrogable según las circunstancias, debe argumentar su posición y poner a disposición del Wali o de su delegado el correspondiente expediente administrativo. Si de su análisis resulta que la actuación de la Administración contraviene los principios de justicia y equidad, además de presentarle un conjunto de observaciones y propuestas a implementar, le exige un informe escrito sobre el desenlace del caso. A ser el objeto de la queja imputable a un error de un funcionario o a una irregularidad en su actuación, el órgano instructor eleva su Informe al jefe de la Administración implicada instándole a tomar las medidas pertinentes para dar solución a la queja.

La ley marroquí establece que todo acto impeditivo de la investigación del órgano instructor por parte de funcionarios que, por su negligencia o pasividad, no respeten el plazo fijado para pronunciarse sobre el objeto del litigio o para responder a las observaciones que le hayan sido comunicadas o cualquier negativa a la prestación del apoyo necesario para la investigación del caso, puede dar lugar a un Informe especial dirigido al Primer ministro.

40 Ibidem, págs. 362-363. 
Aún más exigente es la regulación española ${ }^{41}$ que no sólo establece un mandato de colaboración con el Defensor del Pueblo sino que prioriza tal colaboración otorgándole un "carácter preferente y urgente".

En definitiva, se trata a este respecto de un enunciado muy ambicioso por cuanto el deber de colaboración que establece eleva la función del Ombudsman en ambos países equiparándola en importancia a la de los más altos órganos constitucionales del Estado.

Resulta interesante destacar que si el Wali, en el curso de su investigación, estima que la aplicación rigurosa de una norma jurídica por parte de la Administración sea susceptible de generar perjuicios para los administrados, puede proponer al Primer Ministro introducir las reformas pertinentes.

En el caso de tratarse de las solicitudes de arreglo rápido y equitativo, cuya presentación se asemeja al procedimiento exigido para las quejas y reclamaciones, el Wali o su delegado, envía una copia de dicha solicitud a la otra parte instándola a informar sobre su posición en el plazo de un mes prorrogable si es necesario. La respuesta favorable de la Administración da lugar al despliegue de una labor mediadora y de conciliación entre ambas partes, similar a la empleada para las quejas y reclamaciones, en pos de acercar posturas y, en su caso, llegar a un acuerdo que debe recogerse en un Informe firmado tanto por el mediador como por las dos partes

\section{INFORMES DEL WALI AL MADALIM ${ }^{42}$ Y DE LOS DELEGADOS}

Si en el caso del "Médiateur" francés la rendición de cuentas es doble por cuanto el Informe debe ser presentado tanto al Parlamento como al Presidente de la República, en el derecho español, en razón de la configuración del Defensor del Pueblo como alto comisionado de las Cortes Generales, se ha optado por crear una comisión mixta en dichas Cortes ${ }^{43}$ como cauce de su relación más eficaz con el Parlamento como unidad institucional. El Defensor del Pueblo deberá presentar así a las Cortes Generales por expresa previsión constitucional, en el periodo ordinario de sesiones, un Informe anual de la actividad llevada a cabo. Dicho Informe ha de recoger el número y tipo de quejas presentadas; de aquellas que hubiesen sido rechazadas y de sus causas, así como de las que fueron objeto de investigación y el resultado de las mismas, con especificación de las sugerencias o recomendaciones admitidas por las Administraciones Públicas. El referido Informe, junto al balance de su gestión proporciona una visión de conjunto de las relaciones de la Administración con el ciudadano. Asimismo, cuando las circunstancias así lo aconsejen, ya sea por la gravedad de los hechos o por la

41 Vid. artículo 19 de la LODP.

42 Véase los últimos informes en: http://www.diwan-almadhalim.ma/admin/download/ upload/Rapport2006-2007.pdf

43 L.O. 2/1992 
urgencia con que deben ser reconocidos, puede presentar Informes extraordinarios $^{44}$

En el ordenamiento jurídico marroquí tanto las disposiciones estatutarias como reglamentarias del Diwan establecen que el titular del órgano elaborará tres tipos de Informes.

El primero es de periodicidad anual y se somete al monarca, previéndose la posibilidad de su publicación total o parcial en el Boletín Oficial del Reino. Recoge tanto un análisis cuantitativo y cualitativo de los asuntos de los que ha conocido el Diwan Al Madalim con mención de su situación financiera como el programa de actividades a corto y medio plazo.

El segundo, elevado al Primer ministro, es el prototipo de su actividad pre-legislativa en cuanto contiene sugerencias de alcance general sobre las medidas susceptibles de implementar los principios de justicia. Asimismo, en este Informe se denuncia la negativa de la Administración a ejecutar las decisiones dictadas en su contra y se señalan los disfuncionamientos detectados durante las investigaciones emprendidas por los órganos instructores de los expedientes de quejas que le han sido sometidos.

El último Informe se remite al Consejo Consultivo de los Derechos Humanos poniendo en su conocimiento las violaciones de derechos y exponiendo los asuntos relativos a su promoción y consolidación en el límite de sus competencias.

Asimismo, los delegados ministeriales y regionales están obligados en virtud del artículo 31 del Reglamento a someter trimestralmente al Wali Al Madalim un Informe sobre el balance du sus actividades. Este debe recoger una relación de los asuntos tratados distinguiendo ente las quejas o reclamaciones y las solicitudes de arreglo. Se precisa, también, elaborar un estudio detallado de las gestiones exitosas y de las acciones cuyo fracaso resulta imputable a la falta de implicación de la Administración o que simplemente se debe a su normal actuación de acuerdo con los principios legales que rigen su actividad.

Por último, estos Informes deben hacer clara referencia a las disfunciones en el funcionamiento de la Administración elevando, en su caso, propuesta de reforma.

Resulta aquí de interés recalcar la trascendencia de la publicidad que habría que darle a los referidos Informes por cuanto constituyen un remedio eficaz frente a la corrupción o la injusticia, y como medio de control de las veleidades y arbitrariedades de la Administración, tal como sirvió de freno a las arbitrariedades de los jueces con la introducción de las audiencias públicas en la Administración de justicia.

En el mismo sentido, los Informes del Diwan Al Madalim deben tener una vocación pública ya que sirven tanto para publicitar su labor y así poder reclamar más ámbitos de competencia como para denunciar aquellos comportamientos que desoigan sus recomendaciones.

44 Tanto éstos como los Informes ordinarios se publican en el Boletín Oficial de las Cortes. 
Más aun, en pos de apuntalar sus "autocritas" ante su falta de "potestas", y de consolidarse como nexo estratégico entre la sociedad y la Administración, el Ombudsman ha de abrirse a los medios de comunicación en cuanto amplificadores de su voz. Tanto los derechos como sus defensores pueden necesitar de la prensa a pesar de que sus intereses no son siempre coincidentes.

\section{REFLEXIONES FINALES}

De todo lo expuesto en estas breves notas parece claro que la acción del Diwan Al Madalim es tanto de índole curativa como preventiva. En el primer plano, desempeña, sin base normativa alguna, el papel de árbitro en razón de la imparcialidad que se predica de su labor y en su toma de posición respecto de los litigios que se le plantean. En el mismo sentido impulsa, y aquí radica el secreto de la institución, la corrección de las decisiones y agiliza, en la medida de lo posible, el tratamiento de las cuestiones a él sometidas. En el segundo, de naturaleza preventiva, a diferencia de los tribunales administrativos, puede solicitar que se realicen modificaciones de prácticas, directivas y políticas administrativas que, a pesar de su legalidad, carecen de razonabilidad por cuanto resultan inútilmente entorpecedores del ejercicio de los derechos o que pueden suponer cargas injustificadas para los ciudadanos.

$\mathrm{Si}$ en términos generales el Defensor del Pueblo español y El Diwan Al Madalim marroquí responden a los mismos objetivos, las diferencias entre ambos se aprecian en variados y destacados aspectos. El primero se debe a que si en el ordenamiento español el Defensor del Pueblo es un órgano constitucional protegido por el procedimiento de reforma de la Constitución, en Marruecos el Diwan Al Madalim carece de rango constitucional aunque su creación regia le dota del prestigio necesario para su funcionamiento. Además, la lectura del articulado tanto del dahir como del reglamento muestra que el Diwan sólo interviene a instancias de los afectados por la incorrecta actuación de la Administración, pero nunca de oficio. Ello, sin lugar a duda, merma considerablemente su eficacia. Por un lado, el carácter tasado de sus atribuciones limita su función de garante de la legitimidad de ejercicio del poder, que, al fin y al cabo, es el cumplimiento de los estándares de transparencia y justificación, y le resta flexibilidad para adaptarse a los cambios vertiginosos que acontecen en la sociedad moderna. Por otro, su carencia de la iniciativa propia o de la "capacidad automotriz" no le permite desplegar una función inspectora y le priva de la posibilidad de identificar necesidades sin concretar o carentes de cauces para su manifestación. Atribución que redundaría indefectiblemente en beneficio de categorías sociales prácticamente sin voz, e incluso serviría de medio de expresión de los intereses sociales difusos sin una vía legítima que les haga más visibles y permita su inclusión en la agenda política. Por el contrario, el Defensor del Pueblo español está facultado para impulsar de oficio las investigaciones pertinentes al esclarecimiento 
de los actos y resoluciones de las administraciones públicas y sus agentes, en relación con los ciudadanos; a todo ello se añade que puede accionar el procedimiento de recurso de inconstitucionalidad, siendo ello imposible en Marruecos debido a que el control de constitucionalidad es de naturaleza previa. Además si el Defensor está facultado para interponer el recurso de amparo en defensa de los derechos fundamentales, la función del Diwan es a todas luces de supervisión de la Administración a petición del interesado, configurándose dicha labor como una función autónoma respecto de la de defensa de los derechos. Ésta, así como la salvaguarda de los principios conformadores del Estado de Derecho vienen atribuidas al orden jurisdiccional y, en su caso, al Consejo Consultivo de los Derechos Humanos.

En aras de fortalecer la labor del Diwan Al Madalim sería oportuno crear delegados sectoriales que podrían coadyuvar la labor del Wali Al Madalim desarrollando Informes especiales más profundos debido a su intensa presencia en el medio, que, además, convertirían a este órgano en un referente directo para todos los sectores. A este respecto, podría servir el modelo español del defensor del menor, el defensor universitario, etc. En el mismo sentido, la implantación de Ombudsmen locales podría servir de puente, merced a su labor mediadora, qui est une forme de justice douce par opposition à la justice traditionnelle, entre las posturas de los ciudadanos y la de la Administración local, consiguiendo de este modo un incremento en la participación.

Cabe apuntar asimismo que buena parte de la eficacia del Diwan Al Madalim, su eficacia depende de la virtualidad de sus Informes anuales. La persuasión dispone de sus propios medios operativos que garantizan incluso una eficacia a veces superior, o al menos más ágil, que la derivada de los medios de carácter coactivo o vinculante. Así, las resoluciones del Ombudsman marroquí, ya sean recomendaciones o sugerencias, así como los planteamientos y los análisis contenidos en los Informes afectan directamente a la sociedad por lo que podrían tener una eficacia innegable si se combinan de forma hábil y oportuna con los recursos sociales.

$$
* * *
$$

TitLe: The Moroccan Ombudsman or Diwan Al Madalim under the Spanish Experience.

ABSTRACT: This article deals with the organic and functional features of the Moroccan Ombubsman or Diwan Al Madalim as an institution. This institution falls within the traditional monarchical logic about justice and which is modulated by the new legal regulations in which it is inscribed. The analysis of this figure is carried out in the light of the Spanish experience which gives the force of constitutional law to the figure of the Ombudman so this figure reaches a highest point regarding its functions. In this view, thanks to this position, in the Spanish legal system the Spanish Ombudsman can act ex-offico- something that his Moroccan cannot do - so be has a wider range of functions than his Moroccan counterpart. Notwithstanding this figure has been positively received by both the citizenship and the legal doctrine, the Moroccan Ombudsman 's functions as a guarantee of the legitimacy of the normal ruling becomes limited and when he tries to give his power is restricted when trying to give impulse to the disadvantaged social classes' concerns or when trying to express social interests. 
RESUMEN: El artículo trata de exponer los rasgos orgánicos y funcionales de la institución del Ombudsman marroqui o Diwan Al Madalim, institución inscrita en una lógica tradicional monárquica de justicia y cuyo funcionamiento se ve modulado por el nuevo ordenamiento en el que se inserta. Su análisis se hace a la luz de la experiencia española que otorga al Defensor del Pueblo un rango constitucional, haciendo que el alcance de sus funciones sea más amplio. Amplitud aún más acentuada por la posibilidad de actuar de oficio de la que carece su bomólogo marroquí. Éste que, a pesar de su buena acogida por los ciudadanos en general, y por la doctrina en particular, ve limitada su función de garante cotidiano de la legitimidad de ejercicio del poder y restringida su posibilidad de poder impulsar la satisfacción de las inquietudes de las categorias sociales desfavorecidas ni de expresar los intereses sociales difusos.

KeY Words: Ombudsman. Complaint. Administration. Mediation.

Palabras Clave: Defensor del Pueblo. Quejas. Administración. Mediación

FECHA DE RECEPCIÓN: 05.02.2010. FeCHA DE ACEPTACIÓN: 28.07.2010. 